\title{
PATRIMÔNIO, ARQUEOLOGIA E COMUNIDADES: DA VIOLÊNCIA EPISTÊMICA À CONSTRUÇÃO DE UM PASSADO MÚLTIPLO
}

\section{Mariana Zanchetta Otaviano ${ }^{i}$}

Resumo: Este texto é o resultado da palestra exposta na mesa redonda "Desafios da Preservação: patrimônio de quem para quem?" proferida na "I Semana de Arqueologia da UFPE: Prospectando Novos Olhares" onde busquei trazer para a discussão questões acerca dos usos e abusos do patrimônio, refletir sobre ações de educação patrimonial e como os produtores de conhecimento científico muitas vezes fazem um movimento de opressão e subjugação de conhecimentos tradicionais. Desse modo, provoquei questões contemporâneas relacionadas à prática arqueológica e a construção do conhecimento arqueológico. Partindo dessas ideias, contestamos a existência de uma única verdade arqueológica que se valida por ser cientificamente comprovada e evidenciamos os silenciamentos das vozes e as violências epistêmicas que realizamos em nossas pesquisas. Admitindo que há uma relação de poder e tensão na produção de conhecimento, tentei mostrar que existem diferentes versões para o passado e que o conhecimento acadêmico não é único, mesmo que hierarquize e verticalize as formas de conhecer. PalavrasChaves: Patrimônio; Arqueologia; Construção do Conhecimento.

i Doutoranda do Programa de Pós-Graduação em Arqueologia da Universidade Federal de Pernambuco - UFPE mariana.arqueologia@gmail.com

\begin{abstract}
This text is the result of the talk presented at the round table "Challenges of Preservation: whose heritage for whom?" Given at "I Archeology Week of UFPE: Prospecting New Looks" where I sought to bring to the discussion questions about the uses and abuses of heritage, reflect on heritage education actions and how the producers of scientific knowledge often make a movement of oppression and subjugation of traditional knowledge. Thus, I sought to problematize contemporary issues related to archaeological practice and the construction of archaeological knowledge. Starting from these ideas, we contest the existence of a single archaeological truth that validates itself for being scientifically proven and evidence the silences of the voices and the epistemic violence that we performed in our research. Admitting that there is a relationship of power and tension in the production of knowledge, I have tried to show that there are several versions to the past and that academic knowledge is not unique, even though it hierarchizes and verticalizes ways of knowing. Keywords: Heritage; Archeology; Knowledge Building
\end{abstract}




\section{Introdução}

Muitas vezes, repetimos as palavras patrimônio ou educação patrimonial sem nos atentarmos para as implicações políticas que elas carregam, por isso, achei interessante começar minha fala apresentando algumas questões, mesmo que superficialmente, para refletirmos sobre isso. Por meio do patrimônio foram inventadas as tradições nacionais, segundo o historiador Eric Hobsbawm (1984), tais tradições foram criadas, após as Revoluções Francesa e Industrial, a partir do lugar conferido pelo poder político do Estado.

No nosso país, as definições do que constituem o patrimônio brasileiro estavam também envoltas na construção dos discursos acerca da concepção do que o Estado queria que representasse o passado do Brasil. Esses discursos foram sendo estabelecidos em grande parte na época da fundação do SPHAN, em janeiro de 1937, instituído como órgão oficial de preservação do patrimônio cultural brasileiro. No momento dessas reflexões, necessitava-se de um passado que exaltasse o que seria autenticamente nacional, abordando os pensamentos inerentes à "fundação da nação", com o objetivo de preservar a cultura brasileira e fortalecer a identidade nacional. Mas como fortalecer a identidade nacional e a cultura brasileira? Rodrigo Melo Franco (que delineou o pensamento do SPHAN) defendia que a cultura brasileira era aquela herdada do colonizador europeu, sendo assim, o barroco daria status e vincularia o Brasil à história da Arte Universal.

O barroco torna-se tema central: esse estilo artístico/arquitetônico acabaria por se transformar em uma adaptação de tudo o que seria relevante para eleger a identidade nacional relacionada à Europa, além de estar associado a uma ideia cosmopolita e universal, inerentes ao espírito moderno predominante na época.

Desse modo, a arquitetura barroca materializaria a nação e o patrimônio cultural brasileiro seria inserido nessa áurea estética, preservando suas particularidades, o que the conferia sua própria identidade, mas que não deixava de estar vinculada ao colonizador (Otaviano, 2017). Todos esses esforços objetivavam tanto a proteção do patrimônio edificado quanto a inserção do Brasil no mundo "civilizado", entretanto, a construção de uma memória, também resultou na edificação de uma tradição forjada do que seria a nação, enaltecendo os grandes monumentos. 
O escritor e intelectual Mário de Andrade, ao escrever um anteprojeto de lei para a criação do SPHAN, já defendia uma concepção de patrimônio e história do Brasil que contemplassem os povos até então marginalizados, como negros, mestiços e indígenas, além disso, também discutia a imaterialidade do patrimônio, como o folclore, contos, danças e histórias populares, que só obteve uma legislação específica em 2000 (Decreto no 3551, institui o registro de bens culturais de natureza imaterial). As ideias de Mario de Andrade foram duramente combatidas por Carlos Drummond de Andrade, que defendia que as heranças nacionais seriam aquelas ligadas à Europa.

Na década de 1970 inicia-se um rompimento com paradigmas mecânicos que são atribuídos na lida cotidiana com o patrimônio cultural. Quais são os usos culturais da cultura? Quem está se beneficiando desses usos? Esses valores estão relacionados especialmente ao que a sociedade atribui como sendo importante para ela, configurando assim o patrimônio e sua preservação como um fato social. Há um campo de valores envolto aos bens culturais, mas esses não podem ser impostos e devem tanger especialmente o âmbito social.

Em 1988, por meio da Constituição Federal, a cultura e o patrimônio passaram a ter uma maior aproximação com a questão antropológica, corporificando relações simbólicas, de saber e da prática, além das diferentes visões de mundo e das identidades culturais e sociais. A inserção da esfera imaterial no entendimento de patrimônio, como colocado na Constituição, extrapola o sentido de bem edificado, encarnado nos edifícios e obras de arte. A dimensão intangível passa ser cada vez mais compreendida como algo integrado às manifestações culturais, corporificando identidades e significados a distintos grupos sociais.

O Estado tem o poder declaratório, mas os bens são significados pela comunidade, nesse caminho, os fatos memoráveis começam a dar espaço para o reconhecimento de uma memória coletiva, construída pela diversidade da população brasileira. Antes, um bem cultural, era eleito por uma elite intelectual, de acordo com seus princípios de belo e de arte, representando assim um pensamento hegemônico e eurocêntrico. Hoje uma nova noção de bem está em vigor e os desafios estão concentrados em como identificar, proteger e lidar com a ambivalência do poder público e a comunidade, sendo a última cada vez mais incluída nesses processos, adquirindo caráter protagonista.

A Educação Patrimonial é um meio que nós, arqueólogos, podemos utilizar para corroborar diferentes perspectivas na construção do que é o patrimônio e quem ele representa. De 
acordo com a Portaria 137 de 2016 do Iphan, entende-se por Educação Patrimonial os processos educativos formais e não formais construídos de forma coletiva e dialógica, que têm como foco o patrimônio cultural socialmente apropriado como recurso para a compreensão socio histórica das referências culturais, a fim de colaborar para seu reconhecimento, valorização e preservação.

As atividades de Educação Patrimonial são parte das exigências do Iphan para o trabalho da arqueologia no âmbito do licenciamento ambiental. Em 2015 essa exigência passou a ser mais rigorosa, exigindo projetos e trabalhos com consistência pedagógica e com equipes multidisciplinares. Essa exigência legal faz com que os trabalhos de arqueologia se aproximem mais das comunidades impactadas e do público em geral. Essa tendência já vem sendo observada há pelo menos trinta anos em países da Europa e nos Estados Unidos no âmbito da Arqueologia Preventiva.

No Brasil, a necessidade de cumprir a legislação, traz para o cerne da discussão a questão relacionada ao envolvimento, de fato, que a arqueologia tem feito com as comunidades. Será que nós somente nos preocupamos com essa questão devido às exigências legais? Felizmente posso dizer que não, observamos no Brasil, mesmo que de maneira incipiente, trabalhos que trazem, desde a questão da extroversão do conhecimento arqueológico, a pesquisas que corporificam em suas perspectivas, diferentes vozes. Estas pesquisas, tanto no Brasil, quanto na Latino América, recebem diversificados nomes, tais como Arqueologia Pública, Arqueologia Social, Arqueologia Colaborativa, Arqueologia Relacional, Arqueologia Comunitária e Arqueologia do Presente. O envolvimento da arqueologia com o Neoliberalismo trouxe responsabilidades éticas com as comunidades afetadas, obviamente não sou inocente em admitir que todas as pesquisas arqueológicas inseridas na lógica neoliberal trazem a questão ética.

Desde fins da década de 1960, movimentos sociais, protagonizados por minorias e grupos subalternos tais como as mulheres, indígenas e de operários impulsionaram novas formas de ver e perceber o mundo e isso acabou influenciando as pesquisas acadêmicas em diferentes áreas, inclusive a arqueologia, que, sob a perspectiva pós-processual, adquire maior ênfase no que diz respeito aos caracteres econômicos, sociais, simbólicos dentre outros (Otaviano, 2017). 
Gostaria de abrir um parêntese e explicar o que é minoria, uma vez que, percebi que é constante as pessoas associarem este conceito a uma expressão numérica, ser minoria não é ser menos ou menor, segundo Hannah Arendt (2008), minorias são aqueles grupos que estão inseridos em uma sociedade e, devido aos seus aspectos econômicos, sociais, culturais, físicos ou religiosos são marginalizados. Pois bem, todas estas implicações políticas trazem para a disciplina arqueológica o fato de que o passado (ou seja, a construção do passado) possui ressonâncias políticas no presente. As possibilidades interpretativas de materiais arqueológicos e seus limites passam a ir além da comunicação científica e a extroversão do conhecimento arqueológico.

Em contexto mundial, podemos citar a fundação, em 1986, do World Archaeological Congress (WAC), um movimento não governamental que tem como principal objetivo discutir e diminuir as desigualdades sociais atuais decorrentes do colonialismo por meio da construção crítica, engajada e descolonizada do passado, com a participação das minorias. Ian Hodder (2008), defendendo uma arqueologia reflexiva, chamou a atenção para a importância do envolvimento de grupos subordinados para a interpretação do passado, criando assim o conceito de multivocalidade.

Multivocalidade é uma forma de constituir novas interpretações arqueológicas, trazendo vozes que ficaram às margens da construção dos discursos oficiais arqueológicos, para que eles próprios realizem suas interpretações e representações sobre o passado. Assim como o patrimônio representa, em certos momentos, as classes dominantes, não podemos deixar de entender que o conhecimento e como ele é produzido academicamente também pode ser uma forma de dominação. Alejandro Haber (2016) nos fala dos discursos culturais hegemônicos, que excluem identidades e experiências subjetivas. Segundo suas palavras, a arqueologia leva em seu interior a violência que consiste em mover para os objetos a ruptura metafísica de acordo com a qual a subjetividade colonial se constitui como hegemônica.

A colonialidade do conhecimento é epistêmica, onde, por um lado, são utilizadas formas supostamente superiores, universais, científicas, racionais e por outro lado, o inferior, o local, o supersticioso, o conhecimento falso. Quando produzimos uma arqueologia embasada em uma colonialidade do conhecimento, nós, por consequência, estamos realizando a violência epistêmica. Quando elegemos conhecimentos mais ou menos superiores, quando utilizamos formas científicas para contrapor e questionar os conhecimentos locais e tradicionais, quando usamos a racionalidade em detrimento de subjetividades, e quando trabalhamos com 
comunidades, agregando seus saberes aos nossos discursos sem dar a devida autoria às mesmas, nós estamos praticando uma violência simbólica. Existem esforços vindos da América do Sul, para questionar e quebrar a violência epistêmica, segundo Haber (2016), podemos começar pelos caminhos de: uma abordagem crítica das formas como a arqueologia contribui para a colonialidade e uma exposição variada de arqueologias colaborativas e expressões do conhecimento subalterno.

Então, nesse sentido, uma arqueologia que esteja atenta para a ruptura de violências epistêmicas, teria que combinar conhecimentos e princípios diferentes para construir o passado, considerando a diversidade de pontos de vista dos sujeitos envolvidos na gestão do patrimônio arqueológico e se atentando para as complexas inter-relações culturais, políticas, sociais, dentre outras que existem entre os artefatos arqueológicos e as pessoas (Silva, 2009). De acordo com Ferreira (2008), a consciência desta ligação entre patrimônio e colonialismo (incluindo também o nacionalismo) levou os arqueólogos Michael Shanks e Christopher Tilley (1987) a redefinir o que é arqueologia, para eles não é o estudo do passado, mas sim o estudo do poder. O passado, representado pelo patrimônio arqueológico, pode se tornar um espaço de conflitos, pois, segundo Lúcio Menezes (2008), "o passado ainda não passou", visto que os discursos são construídos no presente.

A materialização do passado, a partir da institucionalização da cultura material, articula representações culturais e de sociedade. Por isso, falo mais uma vez, sobre a necessidade de pensarmos como temos produzido o conhecimento arqueológico e questionar as estruturas de poder. O trabalho nesta direção pode apontar, efetivamente, para a descentralização das políticas de representação do patrimônio focadas no nacionalismo ou no predomínio do Ocidente e de sua força cultural.

Há uma complexa relação entre conhecimento científico, patrimônio e comunidades, entretanto, no Brasil, já podemos observar trabalhos com construção de novas narrativas, onde há uma ressignificação da materialidade, tanto por pesquisadores, quanto pelas comunidades, como exemplo cito Mariana Cabral (TI Wajãpi); Fabíola Silva (Asurini e Kayabi); Márcia Bezerra (Comunidades da Amazônia).

Fazer uma arqueologia engajada em romper epistemes coloniais exige do pesquisador reflexões, reavaliações e autocrítica constantes, representar um passado homogêneo, 
heterossexual e até mesmo sem sujeitos tornou-se tão comum que quando questionamos isso parece que nós estamos errados.

Gostaria que vocês refletissem comigo nessa frase: Conhecer a pré-história do Nordeste do Brasil é também uma necessidade essencial para sensibilizar a consciência nacional sobre os povos indígenas, da urgência de parar o genocídio físico e cultural, que continua sob formas encobertas (Pessis, 2013). Agora pergunto a vocês, qual é a nossa responsabilidade, enquanto arqueólogos, no silenciamento dos povos indígenas do Brasil? Por exemplo, já li trabalhos que falam de formas e funções de vasilhas cerâmicas, de estilos decorativos, de registros rupestres, de tipos de ferramentas líticas, que simplesmente versam sobre a materialidade, as coisas pelas coisas, sem colocar um ou vários sujeitos na construção dessa cultura material. Será que se nós nos preocupássemos em construir um conhecimento que não fosse somente autofágico, mas que mostrasse o protagonismo das pessoas na elaboração da cultura material, nós não poderíamos ter dado destaque para os povos indígenas e assim, com os nossos trabalhos, ajudar nas causas deles?

A historiografia oficial deu conta de silenciar os povos indígenas, e nós, quando simplesmente nos "esquecemos" de colocar em nossos trabalhos que, quem produziu toda essa materialidade pré-colonial que estudamos, foram os povos nativos do Brasil, também temos nossa responsabilidade no silenciamento dessas comunidades. Não estou dizendo que é preciso chegar a uma determinada etnia, mas que, ao menos, colocássemos em nossas pesquisas um levantamento etnohistórico, inferindo sobre possíveis grupos, mostrando agentes ativos da construção dessa materialidade e realçar que as tecnologias e expressões culturais existem neste território muito antes da chegada dos colonizadores. É também o conhecimento a respeito dos grupos conhecidos pela etnografia que nos permite levantar hipóteses, propor interpretações e repensar as evidências arqueológicas.

Além da construção de uma história de longa duração, não podemos deixar de ponderar aqui os efeitos políticos no presente que as pesquisas arqueológicas possuem, para inclusive corroborar o direito a territórios indígenas, um exemplo disso são os trabalhos de Jorge Eremites no Mato Grosso do Sul (grupos Guató e Kaiowá). Nós não podemos escolher ficar mudos quando produzimos conhecimento, somos seres políticos e nossas pesquisas também expressam isso. O nosso silenciamento nos coloca do lado do opressor. A Arqueologia da Repressão e da Resistência, por exemplo, se debruça em estudar as ditaduras civis-militares que se desenvolveram entre as décadas de 1960 a 1980 na América Latina. Estes regimes 
foram marcados pela violência e a violação dos direitos humanos. Muitos ignoram a repressão, os desaparecimentos, as torturas e as detenções ilegais que instauraram uma época de terror. O esquecimento destes crimes políticos passa a ser evidenciado a partir dos estudos das materialidades desta época, construindo as histórias subalternas que foram silenciadas pelo golpe de 1964 no Brasil.

Sendo assim, construir um passado múltiplo e incluir as vozes silenciadas ao longo de anos de produção de conhecimento hegemônico e de violência epistêmica, é, a meu ver, um dever político da arqueologia, nós podemos transformar fragmentos de cultura material em novas histórias daqueles que foram historicamente silenciados.

Em nossas pesquisas e na nossa lida diária com a construção do conhecimento, acredito que sejam importantes questionamentos tais como: Quem tem o direito e controle do passado? A abordagem científica ocidental para a teoria e o método arqueológico é a melhor maneira de interpretar o passado? Quem a arqueologia tem beneficiado? Aproveito para fazer esses questionamentos agora, pois temo que no futuro nós, que tanto temos silenciado, também sejamos silenciados. Como podemos nós, arqueólogos, ficar do lado dos que oprimem? Como podemos nós, apoiar o totalitarismo e a intolerância quando fazemos trabalhos que são destinados a mostrar a diversidade cultural do nosso país? Como podemos nós estar tranquilos quando há a ameaça iminente da extinção de territórios indígenas, quilombolas e do licenciamento ambiental? Como podemos nós escolher estar do lado do opressor mesmo sabendo que seremos oprimidos? Como escolher alguém se opõem às nossas subjetividades e às nossas formas de ser?

A ciência também é caminho de liberdade, de democracia, e pode ser feita diferente. Somente com mais diálogos e com a manutenção dos financiamentos de pesquisa é que teremos mais possibilidades de construir passados e presentes múltiplos. Precisamos das liberdades tanto de expressão como de todas as formas de ser, resistindo para poder existir.

\section{Referências}

ARENDT, H. 2008. Compreender Formação, Exílio e Totalitarismo. Trad. Denise Bottmann. São Paulo: Companhia das Letras.

BEZERRA. M. 2017. Teto e afeto: sobre as pessoas, as coisas e a arqueologia na Amazônia. Belém: Gknoronha. 
CABRAL, M. P. 2014. No tempo das pedras moles: arqueologia e simetria na floresta. 2014. 262 f. Tese, Doutorado em Antropologia, Programa de Pós-Graduação em Antropologia, Instituto de Filosofia e Ciências Humanas, Universidade Federal do Pará, Belém.

EREMITES DE OLIVEIRA, J. 2007. Cultura material e identidade étnica na arqueologia brasileira: um estudo por ocasião da discussão sobre a tradicionalidade da ocupação Kaiowá da Terra Indígena Sucuri'y. Cultura e Sociedade, Goiânia, 10(1): 95-113.

FERREIRA, L. M. 2008. Patrimônio, pós-colonialismo e repatriação arqueológica. Ponta de Lança, São Cristóvão v.1, n. 2, abr.-out.

GNECCO, C. 2012. Escavando arqueologias alternativas. Revista de Arqueologia, [s.i.], v 25, n. 2, p. 08-22, 2012.

HABER, A. 2016. Al outro lado del vestígio: políticas del conocimento y arqueologia indisciplinada. Popayán/CO: Sello.

HOBSBAWM, E. 1984. Introdução: A Invenção das Tradições. In: HOBSBAWM, Eric; RANGER,Terence (orgs.). A Invenção das Tradições. Rio de Janeiro: Paz e Terra.

HODDER, I. 2008. Multivocality and social archaeology: evaluating multiple narratives. New York: Springer, p. 196-200.

OTAVIANO, M. Z. 2017. "O lugar das coisas" Arqueologia pública e descolonização do conhecimento: um estudo de caso em Lagoa de São Vitor - PI. 2017. 66f. Monografia, Trabalho de Conclusão de Curso, Graduação em Arqueologia e Preservação Patrimonial, Curso de Graduação em Arqueologia e Preservação Patrimonial, Universidade Federal do Vale do São Francisco, São Raimundo Nonato.

PESSIS, A-M. 2013. Imagens da Pré-história. Parque Nacional Serra da Capivara. Images de la Prèhistorie; Images from Pre-History, 2ª edição ampliada e atualizada. Fumdham Ed. São Paulo, 320 p. il. color.

SHANKS, M.; TILLEY, C. 1987. Re-Constructing Archaeology. Cambridge, Cambridge University Press.

SILVA, F. A. 2009. Arqueologia e Etnoarqueologia na Aldeia Lalima e na Terra Indígena Kayabi: reflexões sobre Arqueologia Comunitária e Gestão do Patrimônio Arqueológico. Revista do Museu de Arqueologia e Etnologia, São Paulo, v. 19, p. 205-219, 2009. 